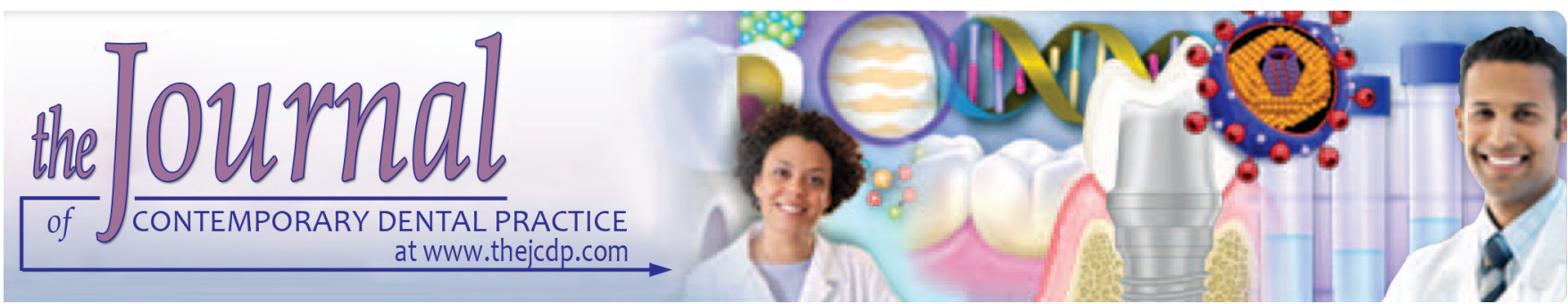

\title{
Predictability of Craniofacial Skeletal Age with Geometric Morphometrics
}

\author{
${ }^{1}$ Antoine Saadé, ${ }^{2}$ Pascal Baron, ${ }^{3}$ Ziad EF Noujeim, ${ }^{4}$ Elie Arouk, ${ }^{5}$ Dany Azar
}

\begin{abstract}
Aim: This study aims to estimate skeletal age of craniofacial shape obtained from cone beam computed tomography (CBCT)-defined facial and basicranial landmarks using geometric morphometrics method in a random sample of growing patients, and explore the correlation between craniofacial shape and skeletal age as determined from hand and wrist radiograph.
\end{abstract}

Materials and methods: Generalized Procrustes analysis (GPA) of craniofacial shape with estimation of centroid size was performed on CBCTs of 48 growing patients (mean age $11.7 \pm 1.5$ years). Greulich and Pyle method for skeletal age assessment were used for correlation with centroid size. Correlation among the variables relied on Pearson's coefficient and its 95\% confidence interval was estimated. The model's $\mathrm{R}^{2}$ was calculated, (Cook's distances, Mahalanobis distances, leverage values, and studentized residuals) and multiple regression analysis performed using the Statistical Package for the Social Sciences (SPSS) version 22.

Results: Mean skeletal age was $11.9 \pm 2.4$ years. Centroid size (151.5 \pm 7.2$)$ was significantly correlated with chronological age $(\mathrm{R}=0.616,95 \% \mathrm{Cl} 0.355-0.789, \mathrm{p}<0.01)$ and skeletal age $(R=0.605,95 \% \mathrm{Cl} 0.331-0.794, p<0.01)$.

${ }^{1}$ Department of Orthodontics and Dento-Facial Orthopedics, Lebanese University, Faculty of Dental Medicine, Hadath, Lebanon

${ }^{2,4}$ Department of Orthodontics Faculty of Dental Surgery, Paul Sabatier University, 3 Chemin des Maraichers, Toulouse, France

${ }^{3}$ Departments of Oral Medicine and Maxillofacial Radiology and Oral and Maxillofacial Surgery, Lebanese University, Faculty of Dental Medicine, Hadath, Lebanon

${ }^{5}$ Department of Palaeobiology and Stratigraphy, Nanjing Institute of Geology and Paleontology, Chinese Academy of Sciences, Nanjing, Jiangsu, China and Department of Natural Sciences, Lebanese University Faculty of Science, Fanar, Lebanon

Corresponding Author: Antoine Saadé, Department of Orthodontics and Dento-Facial Orthopedics, Lebanese University, Faculty of Dental Medicine, Hadath, Lebanon, e-mail: saadeantoine@hotmail.com
Conclusion: A new equation for determining craniofacial skeletal age was developed, using the centroid size of the craniofacial frame, gender, and the known chronological age.

Clinical significance: A CBCT may be used for skeletal age assessment without additional hand wrist radiograph.

Keywords: Centroid size, Cone beam computed tomography, Geometric morphometrics, Prospective cross-sectional study, Skeletal age.

How to cite this article: Saadé A, Baron P, Noujeim ZEF, Arouk E, Azar D. Predictability of Craniofacial Skeletal Age with Geometric Morphometrics. J Contemp Dent Pract 2018;19(12):1494-1501.

\section{Source of support: Nil}

\section{Conflict of interest: None}

\section{INTRODUCTION}

Skeletal age assessment is a common procedure widely used by physicians and other scientists (forensic scientists, orthopedic surgeons, pediatricians, etc.) as well as dentists in orthodontics and dentofacial orthopedics. ${ }^{1}$ Various radiological procedures were reported in the literature to evaluate skeletal age of individuals, using, for instance, the elbow, cervical vertebrae, or clavicle radiographs, but the hand and wrist radiograph is still considered the gold standard. Among the skeletal evaluation methods based on hand and wrist radiograph ${ }^{2-4}$, the Greulich and Pyle's 5 remains the most popular one. ${ }^{6}$ Evaluating skeletal age on radiographs is based on practitioner's experience and ability to assess qualitative morphological criteria, such as the volume of metacarpal bones and epiphysis shapes. Conventional morphometrics is used to measure the size of objects and compare linear distances (or angles between them) to detect morphological similarities and/or differences in a given sample. Knowing the disadvantages in relation with the differences in size and orientation within a sample, geometric morphometrics (GM) approach was developed; this "revolution of quantification" relies 
on statistics and is considered as "the analysis of shape variation and its covariation with other variables". ${ }^{7}$ In comparison with conventional morphometrics (CM), the greatest shift was the emphasis on quantitative variation of objects' shape after superimposition of their configuration. The latter is obtained by plotting specific landmarks (labeled geometric points with 2D or 3D coordinates), localized on object architecture. Analysis of landmark's coordinates in GM requires additional steps to eliminate variations of position, orientation, and scale, during Procrustean superimposition, known as Generalized Procrustes analysis (GPA). ${ }^{8}$ This superimposition is performed on the centroid which is considered as arithmetic mean position of all shapes' points.

The advent of CBCT has obviously facilitated the acquisition of data that previously required several conventional radiation exposures. However, only conservative protocols aiming to reduce ionization time (radiation exposure), with filtration and limitation of field of view will allow $\mathrm{CBCT}$ to be a permanent alternative to $2 \mathrm{D}$ radiology. ${ }^{9}$ While methods of dental age estimation on CBCT are prolific in the scientific literature, ${ }^{10-12}$ only a few publications addressed the use of CBCT for assessment of skeletal age for cervical vertebrae ${ }^{13}$ or midpalatal suture $e^{14}$ maturations. GM was used in both conventional ${ }^{15}$ and 3D methods for skeletal estimation of age. ${ }^{16}$

The current study was undertaken with the following aims:

- To characterize the craniofacial shape obtained from CBCT-defined facial and basicranial landmarks and analyze its variability in a random sample of growing patients using geometric morphometrics method.

- To explore the correlation between craniofacial shape and skeletal age as determined from hand and wrist radiograph, according to Greulich and Pyle (GP) method (1959).

- To derive a stable estimate of skeletal age using craniofacial shape properties.

\section{MATERIALS AND METHODS}

The current study was approved by the Ethical Committee of the Lebanese University (CUEMB 51/2016). It included 48 consecutive participants (30 females and 18 males).

The Enrollment was monocentric and took place in the Department of Orthodontics and Dentofacial Orthopedics, Faculty of Dental Medicine, from May 2016 till November 2017.

Inclusion criteria comprised male or female subjects aged 7 to 15 years requiring orthodontic treatment, having undergone $\mathrm{CBCT}$ and hand-wrist radiographs at the same date and before the initiation of any orthodontic treatment.

Patients with craniofacial anomalies, syndromic diseases, history of growth disorders, and craniofacial trauma were excluded from the sample.
A signed informed consent form was obtained from eligible participants (or their legal representative) before enrollment in the study.

\section{Imaging Techniques}

The CBCT exams were performed on an i-CAT next generation for image acquisition machine (Imaging Sciences International, Hartfield, PA, USA). The participant's head was oriented on Frankfort horizontal plane, and the images were acquired with the following parameters: 0.4 voxel size, $17 \times 13 \mathrm{~cm}$ scan size (field of view), and acquisition time of $10 \mathrm{~s}$. Hand wrist radiographs were obtained, using the $8000 \mathrm{C}$ digital extraoral imaging system (Carestream Health, Inc. Rochester, NY, USA). Besides the chronological age, skeletal age and centroid size of craniofacial shape were assessed for each participant.

\section{Assessment of Skeletal Maturity According to Greulich and Pyle's Atlas (2nd ed., 1959) ${ }^{4}$}

Radiographs of the participant's left hand and wrist were compared with the images listed in the radiographic atlas of Greulich and Pyle in the corresponding section (males or females). The matching image in the atlas provided the skeletal age as recorded by the original authors.

\section{Assessment of Craniofacial Shape and Shape variations using the GM Method}

The used landmarks were considered homologous, located on the neuro matricial growth trigeminal axis as described by Moss. ${ }^{17}$ It is well known that as early as the 4th embryonic week, the "trigeminal hand" with its ramifications, is elaborated [trigeminal ganglion with the trigeminal main branches: ophthalmic branch (V1), maxillary branch (V2) and mandibular branch (V3)]. Around nerve ramifications, different connective tissues leading to bone, cartilage, and muscles are progressively defined, resulting in a stable 3D model shape during growth. ${ }^{18}$

\section{Landmarks list (based on Wilson-Pauwels et al.) ${ }^{19}$ (Fig 1)}

Six bilateral anatomical landmarks (listed below and numbered from 1 to 12) were selected and digitized on each CBCT using AVIZO 3D analysis software (version 8.1.1; FEI Visualization Sciences group, Merignac, France):

- Landmarks 1 and 2: right and left supraorbital foramina (from where a terminal branch of V1, the supraorbital nerve, exits the skull).

- Landmarks 3 and 4: right and left superior orbital fissures, laterally to the anterior opening of the optic canal (from where lacrimal division, frontal division, 

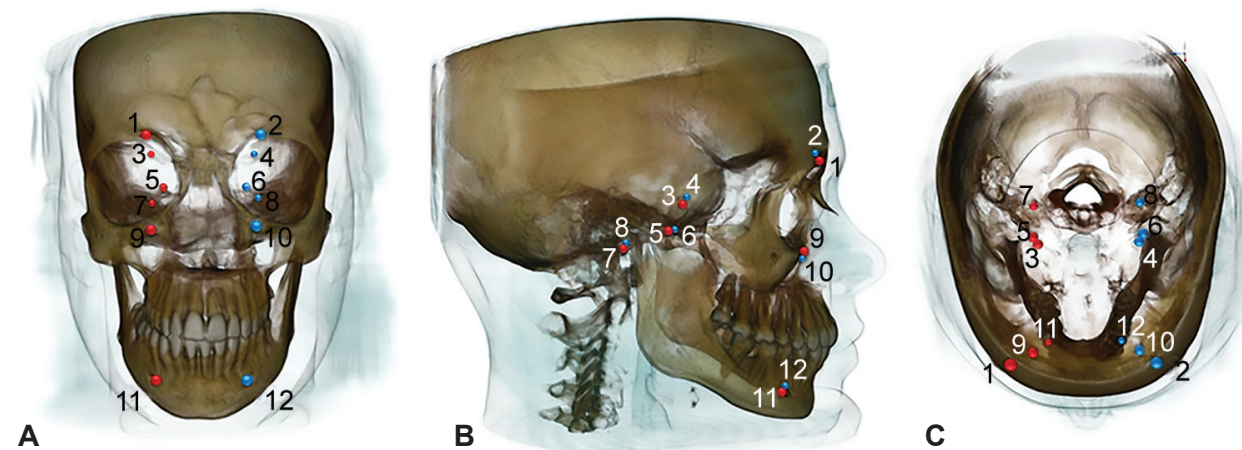

Fig. 1A to C: Landmarks plotted on CBCT. (A) frontal view; (B) lateral view; (C) basal view

and nasociliary branch of V1 exit the skull).

- Landmarks 5 and 6: The most anterior opening of right and left foramen rotundum canals (from where the maxillary branch, V2, exits the skull).

- Landmarks 7 and 8: The most superior aspect of right and left oval foramina (from where V3 and the motor root of the trigeminal nerve exit the skull).

- Landmarks 9 and 10: The most anterior opening of right and left infraorbital foramina (from where a terminal branch of V2, the infraorbital nerve, exits the skull).

- Landmarks 11 and 12: The most anterior opening of right and left mental foramina (from where a terminal branch of V3, the mental nerve, exits the skull).

\section{Determination of Craniofacial Shape Using MorphoJ Software, version 1.06d. ${ }^{20}$}

Landmarks '3D coordinates were captured on MorphoJ. Procrustes fit for the dataset was then performed, to remove non-shape variations, related to position, size, and orientation. The initial step of GPA was to produce a centroid size for each configuration. Landmarks coordinates of the sample were then aligned by principal axes on the homologous points and average shape with a centroid (landmark 13) obtained (Fig. 2). Centroid size is defined as the square root of the sum of squared deviations of landmarks from their centroid. ${ }^{21}$ For each landmark, CBCT derived 3D coordinates ( $x, y$, and $z)$, summing to 36 coordinates per individual.

\section{Centroid Coordinates Calculation}

$$
C_{x}=\frac{\sum_{i=1}^{N} p_{x}^{i}}{N} \quad C_{y}=\frac{\sum_{i=1}^{N} p_{y}^{i}}{N} C_{z}=\frac{\sum_{i=1}^{N} p_{z}^{i}}{N}
$$

Centroid Size (CS) Equation of Craniofacial Shape

$$
\text { size }=\sqrt{\sum_{i=1}^{N}\left(p_{x}^{i}-C_{x}\right)^{2}+\left(p_{y}^{i}-C_{y}\right)^{2}+\left(p_{z}^{i}-C_{z}\right)^{2}}
$$

Finally, the 3D configuration of craniofacial shape ("the wireframe") is obtained after connection of all

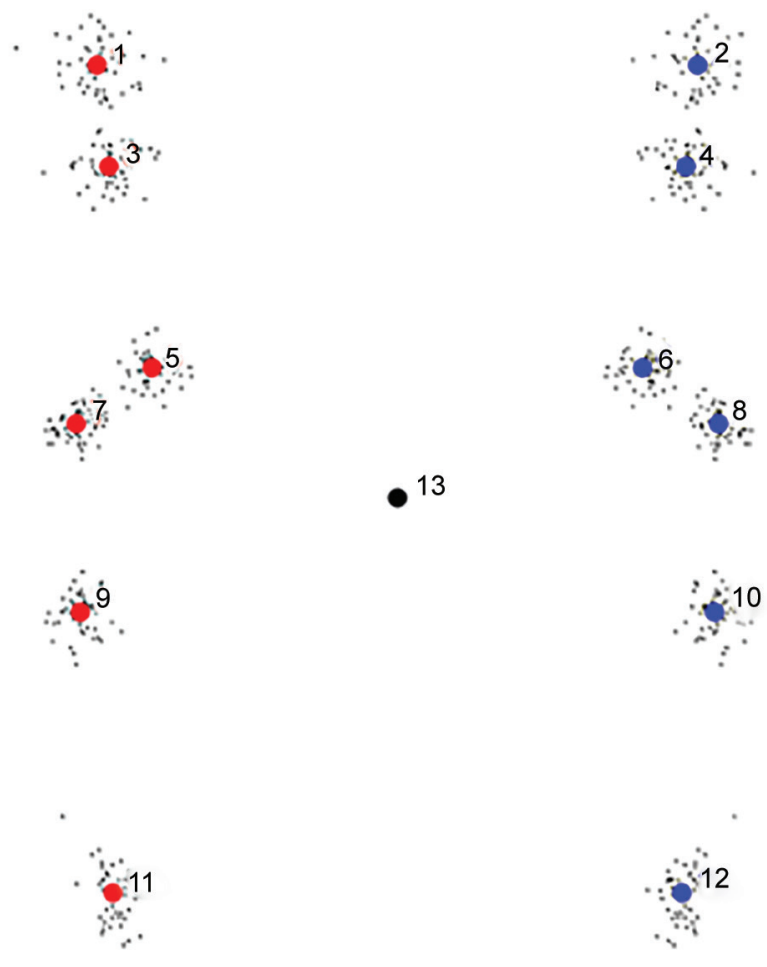

Fig. 2: Procrustes superimposition on centroid with mean average of scattered plots for craniofacial shape, showing the landmarks

bilateral anatomical landmarks (Figs 3A to C).

\section{Reproducibility}

For interobserver agreement, radiographs were evaluated by 2 examiners (AS and EA). For intra observer agreement, 30 CBCTs were randomly selected and re-digitized by main investigator (AS), four weeks following the initial measurement. Lin's concordance correlation coefficient was used to measure intra- and inter-observer agreement.

\section{Statistical Analysis}

The 3D coordinates $(x, y$, and $z$ ) of the landmarks, centroid size, gender, chronological age, and skeletal age, were completed for all participants. Distribution of skeletal age, chronological age, and centroid size was checked for departure from normality using Kolmogorov-Smirnov 
and Shapiro-Wilk statistics, with additional graphical assessment using Quartile-Quartile plots. Correlation among the variables relied on Pearson's coefficient and its $95 \%$ confidence interval was estimated with bootstrapping (bias-corrected and accelerated) based on 1000 samples.

With the assumption of normal distribution of skeletal age, chronological age, and centroid size as assessed by normality statistics and quartile-quartile plots, skeletal age as the dependent variable could be fitted with an identity link (that is, directly, not using any analytical function) with the other predictors in a multiple linear regression model, where skeletal age is the dependent variable and all the other variables are predictors. One model was developed for both genders since gender will be accounted for in the model as a factor, taking the values of 1 for males and 2 for females. The following equation summarizes the multiple linear regression model:

skeletal age $=\beta_{0}+\beta_{1}$. chronological age $+\beta_{2}$. Gender $+\varepsilon$

where $\beta 0$ is the intercept, $\beta 1$ the unstandardized coefficient for chronological age, and $\beta 2$ the unstandardized coefficient for gender, being the residual error.
The model's $\mathrm{R}^{2}$ was calculated, with additional diagnostic statistics (Cook's distances, Mahalanobis distances, leverage values, and Studentized residuals). Multiple regressions were performed using SPSS v22 (IBM Corp. Released 2013. IBM SPSS Statistics for Windows, Version 22.0. Armonk, NY: IBM Corp.).

\section{RESULTS}

The study included 48 consecutive participants (30 females and 18 males). Mean chronological age was $11.78 \pm 1.77$ years for males and $11.59 \pm 1.41$ years for females. Mean skeletal age was $11.0 \pm 2.20$ years for males and $12.51 \pm$ 2.38 years for females (Table 1 ).

As for the whole sample, mean chronological age was $11.7 \pm 1.5$ years, range 7.4 to 14.8 , whereas mean skeletal age was $11.9 \pm 2.4$ years, range 6.0 to 16 years (Table 2). Lin's concordance correlation coefficient was $>0.98$ for all intra-observer and inter-observer measures and for all the dimensions. The centroid size ranged from 127.4 to 164.1 , with a mean of $151.5 \pm 7.2$.

Pearson coefficient between both variables centroid size and skeletal age, showed significant correlation.
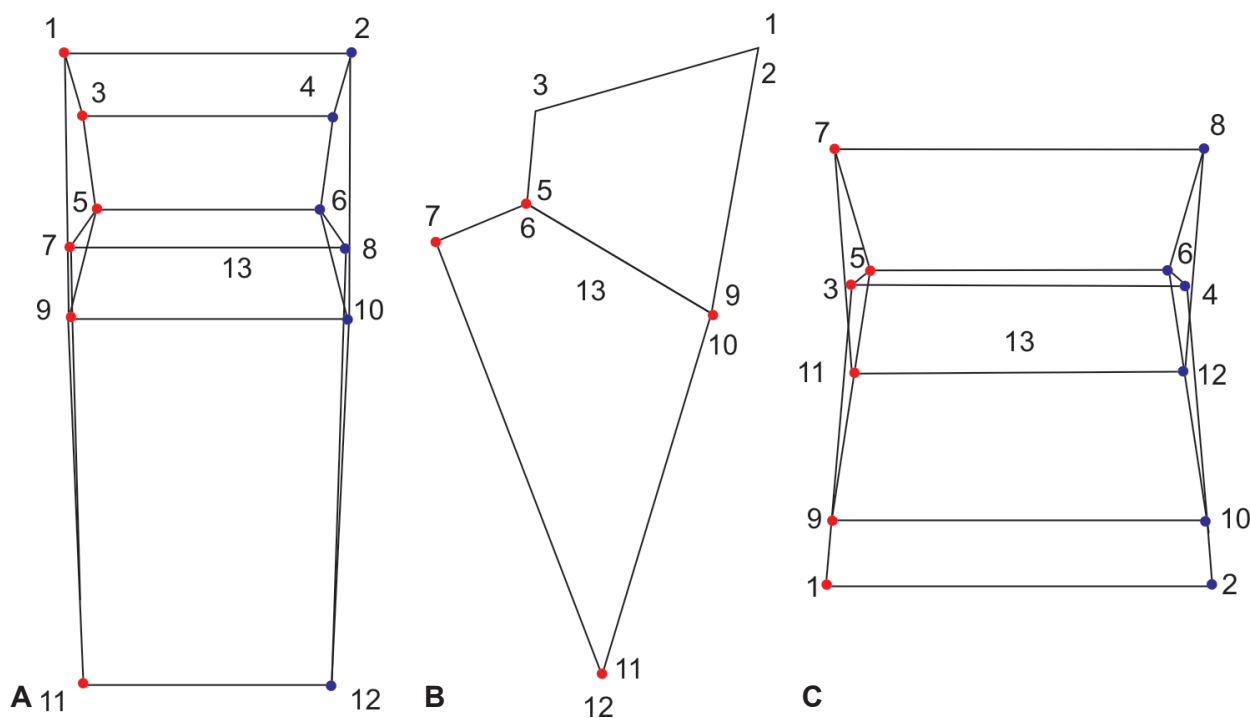

Figs 3A to C: Wireframe of craniofacial shape. (a) frontal view; (b) lateral view; (c) basal view

Table 1: Summary statistics of chronological age and skeletal age by genders

\begin{tabular}{|c|c|c|c|c|c|c|c|}
\hline & & & Mean & Standard deviation & Median & Percentile 25 & Percentile 75 \\
\hline \multirow{4}{*}{ Gender } & \multirow[t]{2}{*}{$\mathrm{M}$} & Chronological age & 11.78 & 1.77 & 11.87 & 11.00 & 12.91 \\
\hline & & Skeletal age & 11.00 & 2.20 & 11.00 & 10.00 & 12.50 \\
\hline & \multirow[t]{2}{*}{$\mathrm{F}$} & Chronological age & 11.59 & 1.41 & 11.54 & 10.41 & 12.58 \\
\hline & & Skeletal age & 12.51 & 2.38 & 13.00 & 11.00 & 14.00 \\
\hline
\end{tabular}

Table 2: Summary statistics for dependant and independent variables

\begin{tabular}{llllll}
\hline & Mean & Median & Std. deviation & Minimum & Maximum \\
\hline Centroid size & 151.5 & 151.9 & 7.2 & 127.4 & 164.1 \\
In Centroid Size & 5.0 & 5.0 & 0.0 & 4.8 & 5.1 \\
Chronological age & 11.7 & 11.6 & 1.5 & 7.4 & 14.8 \\
Skeletal age & 11.9 & 12.0 & 2.4 & 6.0 & 16.0 \\
\hline
\end{tabular}


It was $0.573\left(R^{2}=0.328\right)$ for male group and 0.725 $\left(R^{2}=0.526\right)$ for female group $(p<0.01)($ Graph 1$)$. As for the whole sample, centroid size was significantly correlated with chronological age $(\mathrm{R}=0.616,95 \%$ CI $0.355-0.789$, $\mathrm{p}<0.01)$ and skeletal age $(\mathrm{R}=0.605,95 \%$ CI $0.331-0.794$, $\mathrm{p}<0.01$ ) (Graphs 2 and 3).

Using multiple linear regression analysis, centroid size, chronological age, and gender were all independent and good predictors of the dependent variable skeletal age (Table 3 ). The model's adjusted $R^{2}$ (proportion of variance in the dependent variable) was 0.83 , explained by the independent variables. The model's diagnostics were all within acceptable limits (studentized residuals, Mahalanobis distances, Cook's distances, and centered leverage values).

Based on this model, a new equation for determining craniofacial skeletal age was developed, using the centroid size of the craniofacial frame, gender ( 1 assigned for males and 2 for females) and the known chronological age:

Skeletal age $=-13.534+0.059 \times$ Centroid size $+1.809 x$ Gender $+1.160 \times$ Chronological age

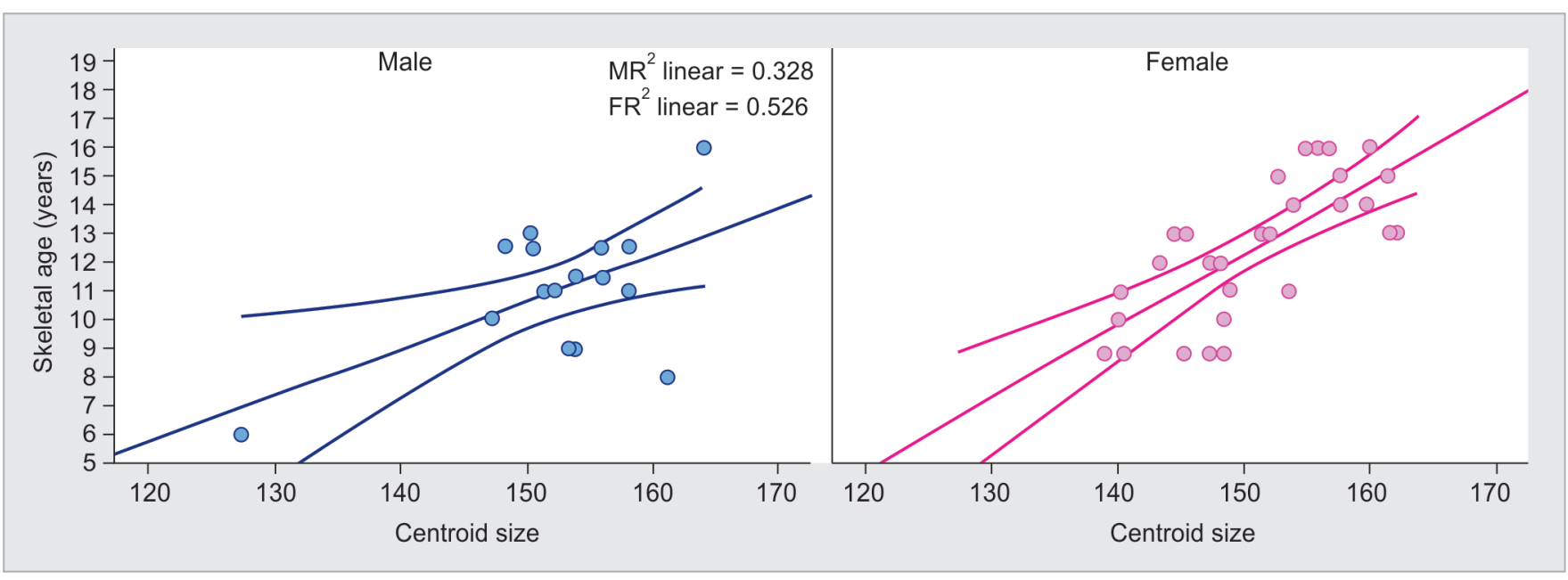

Graph 1: Distribution of centroid size for males and females relative to skeletal age. Dashed lines represent $95 \%$ confidence limit around the mean. R2 denotes coefficient of determination

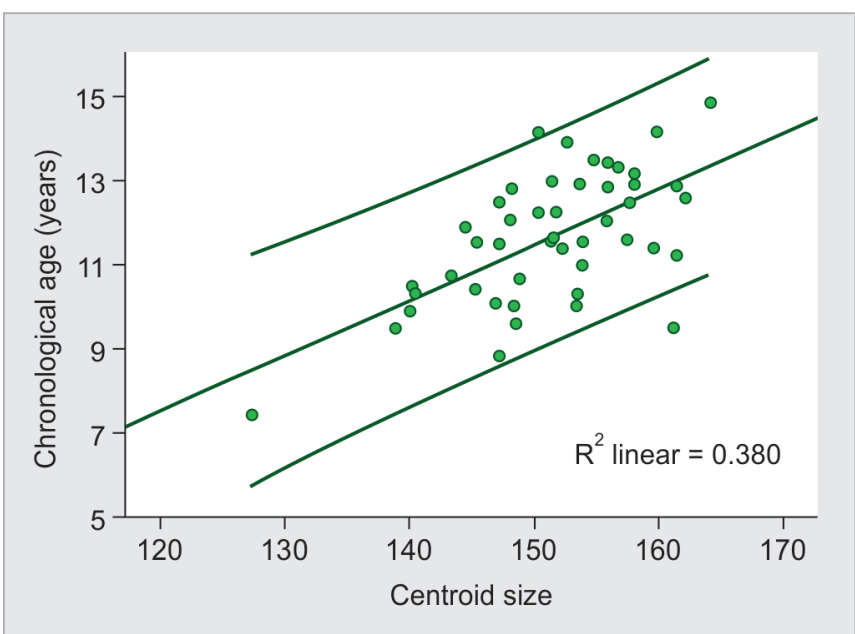

Graph 2: Scattered plots showing correlations between centroid size and chronologic age for the whole sample $(R 2=0.380)$

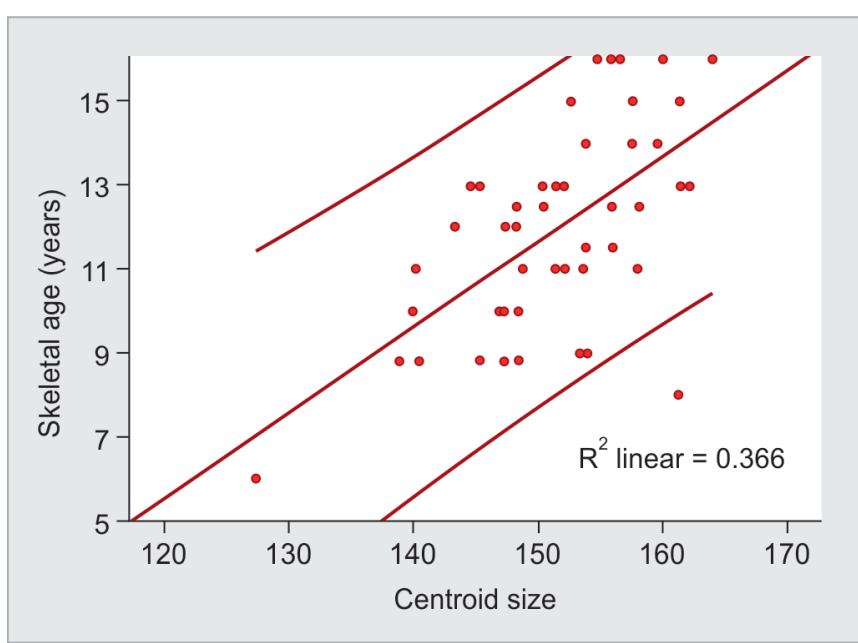

Graph 3: Scattered plots showing correlations between centroid size and skeletal age for the whole sample $(R 2=0.366)$

Table 3: Multiple linear regression model with craniofacial skeletal age as dependent variable.

\begin{tabular}{lllllll}
\hline Parameter & $B$ & Std. Error & Beta & $t$ & $p$-value & $95 \% \mathrm{Cl}(\mathrm{B})$ \\
\hline (Constant) & -13.534 & 3.323 & & -4.073 & 0.000 & {$[-20.232 ;-6.837]$} \\
Centroid size & 0.059 & 0.026 & 0.178 & 2.301 & 0.026 & {$[0.007 ; 0.112]$} \\
Gender* $^{\text {Chronological age }}$ & 1.809 & 0.299 & 0.368 & 6.041 & 0.000 & {$[1.205 ; 2.412]$} \\
\hline
\end{tabular}

B: unstandardized coefficient for the corresponding independent variable.

Std. Error: standard error of the unstandardized coefficient

Beta: standardized coefficient for the corresponding independent variable

95\% Cl: $95 \%$ confidence interval for the unstandardized coefficient

${ }^{*}$ * 1 for male and 2 for female subjects.

$\left.{ }^{* *}\right)$ age in years is between 7 and 15 


\section{DISCUSSION}

Several scientific methods studied the correlation between chronological age and estimation of skeletal age. In the GP method, the observer investigates similarities between patient's radiograph and a matching one in the corresponding Atlas. This assessment relies on the observer's experience, and consequently, could be subjective. In a previous study, we found that correlation between chronological and skeletal age assessment based on GP method was as high as 0.776 for both genders. ${ }^{22}$ This correlation was even higher (0.983) in a sample of 2614 individuals of multi-ethnic origin, using the same method of estimation. ${ }^{23}$ A recent systematic review browsed 658 relevant publications on age estimation based on hand-wrist radiograph; the analysis showed that "variations between studies from different parts of the world were moderate and that difference between GP skeletal age and chronological age rarely exceeded one year for the average of a group in single studies." ${ }^{24}$ Although this method is not always accurate in different populations or age groups, ${ }^{25}$ it remains predictable for chronological age and it is still widely used.

The use of geometric morphometrics allows a wide application in fields like anatomy, ontogenetic and evolutionary allometry, growth and correlation between facial skeletal development and dental crowding. ${ }^{26}$ In several publications, the centroid size was considered as a proxy for growth or age determination, assessed on various sites, among others, the sella turcica, the skull, or the cervical vertebrae. Objectives of these studies have tended to suggest linearity of their models. Braga and Treil reported a method of pediatric skeletal age estimation based on centroid size and two wireframes (facial and basicranial). A linear model was elaborated for the facial frame, whereas no linearity was detected in basicranial frames of males and females older than 10 years. The highest accuracy (52\%) was for a facial wireframe of boys after 10 years of age. ${ }^{16} \mathrm{GM}$ method was used to evaluate the shape of the first four cervical vertebrae and its correlation with skeletal maturation: results suggested that shape alone was not a better predictor for skeletal age than chronological age. The range of correlation between shape and skeletal maturity $\left(0.27<\mathrm{R}^{2}<0.75\right)$ was related to the examined vertebra $(\mathrm{C} 1$, C2, C3 or C4), a combination of vertebrae, and gender. However, the combination of centroid size and age gave higher prediction than shape alone. ${ }^{15}$ These findings were similar to those of the present study in which centroid size and age, in addition to gender, were all combined good predictors for determination of skeletal age $\left(R^{2}=0.83\right)$. In another study, estimation of bone and forensic age using the shapes of cervical vertebrae showed no differences in centroid size according to gender, and for gender comparison, bone and forensic age estimation models for males had the higher explanatory power. A positive correlation between centroid size and skeletal maturity was found: correlation coefficients of centroid size and skeletal maturity (female/male) were, respectively, $0.5882(0.6306 / 0.7418), 0.6284(0.7457 / 0.7838)$, and 0.6370 $(0.7582 / 0.8001)$ at $2 \mathrm{nd}, 3 \mathrm{rd}$, and 4 th cervical vertebrae. ${ }^{27}$ In the results of the present study, the correlation between centroid size and chronological age was $r=0.616$; correlation with skeletal age was also significant ( $R=0.605)$. CBCT images of cervical vertebrae and handwrist radiographic data were also selected in order to propose a skeletal maturity assessment method by developing a statistical regression analysis using centroid size, chronological age, and gender as predictors; the authors reported that when both axial and lateral cervical vertebrae were used together, there was an increase in the Sempé maturation level compared with that when only the chronological age was used. ${ }^{28}$ These results improved the estimating regression models using statistical shape analysis with cervical vertebrae and more accurately when models included centroid size.

Selection of landmarks based on their embryologic origin could be questionable. In the present study, all landmarks were from homogeneous origin related to "trigeminal foramina", however, some are located in the skull's base (i.e. anterior opening of foramen rotundum canal and ovale foramen) while some others are from facial components like maxilla (infraorbital foramen) or mandible (mental foramen), hence from different ontogenies. The body development follows a differential growth pattern known as the cephalocaudal gradient of growth. ${ }^{29}$ This is observed as well in the skull with "craniofacial levels of skull development" where the nasomaxillary complex reaches maturation later than the vault and basicranial complex, whereas the end mandibular growth is achieved later than the maxillary one as stated by Enlow and Hans. ${ }^{30}$ Thus, centroid size might be affected by growth layers. Analysis of developmental covariation of the human vault and skull base stipulates that ontogenic changes were independent of the integration between cranial vault and skull base. ${ }^{31}$ Shape covariation between vault and base was structured by size but centroid size and endocranial volume changes justified different ontogenetic changes.

This study aimed to seek a correlation between the centroid size of the craniofacial shape, chronological and skeletal ages assessed following GP method. Some considerations could be explored aiming to reach a higher accuracy in future research. Results of the present study suggested that the centroid size of a craniofacial frame based on trigeminal landmarks is a good predictor 
to be used for skeletal age determination. Literature is abundant in skeletal assessment methods based on cervical vertebrae, but few references are found ${ }^{15}$ relying on geometric morphometrics to determine skeletal maturation of skull components. Emphasize on additional landmarks with the same anatomical homogeneity in a future study would probably lead to impact centroid size, thus modify the coefficient of determination.

A bigger sample for further research is warranted since it may allow better accuracy and possible results divergence related to gender. More participants with younger age could have modified the correlation centroid size-skeletal age, but ethical considerations refrain from taking an unnecessary $\mathrm{X}$-ray if not indicated for orthodontic treatment.

\section{CONCLUSION}

In the present study, the craniofacial shape obtained from facial and basicranial landmarks defined on CBCT was characterized. Its variability was analyzed in a random sample of growing patients using geometric morphometrics method.

Our study showed a significant correlation between centroid size and chronological age $(R=0.616)$, as well as between centroid size and skeletal age $(R=0.605)$.

Based on multiple linear regression analysis, a new model for skeletal age determination was elaborated. A strong model's predictability was found $\left(R^{2}=0.83\right)$, involving centroid size, chronological age, and gender.

\section{CLINICAL SIGNIFICANCE}

Centroid size of the craniofacial frame is a good predictor of skeletal age. It constitutes an additional stone for the elaboration of new proxy for facial age determination needed in orthodontics, surgery, or forensic purposes, based on individuals' CBCT without the need of other x-ray acquisition.

\section{ACKNOWLEDGMENTS}

The authors wish to thank Drs Rafic Faddoul and Ghassan Sleilaty (Saint Joseph University, Lebanon) for their valuable help in the statistical analyses.

This work is a contribution to the activity of the laboratory "Advanced Micropalaeontology, Biodiversity and Evolution Researches" (AMBER). DA wants to thank the Chinese Academy of Sciences for their support under the CAS President's International Fellowship Initiative (PIFI).

\section{REFERENCES}

1. Zerin JM, Hernandez RJ. Approach to skeletal maturation. Hand Clin 1991 Feb;7(1):53-62.
2. Tanner JM, Whitehouse RH, Cameron N, Marshall WA, Healy MJ, Goldstein H. Assessment of skeletal maturity and prediction of adult height (TW2 method). 2nd ed. London: Academic press 1983. 108 p.

3. Fishman LS. Radiographic evaluation of skeletal maturation. A clinically oriented method based on hand-wrist films. Angle Orthod 1982 Apr;52(2):88-112.

4. Sempé M. Analyse de la maturation squelettique du poignet, de la main et du coude. La pédiatrie au quotidien. 22 applications cliniques. Paris: Editions Inserm, Doin 1987. 509 p.

5. Greulich WW, Pyle SI. Radiographic atlas of skeletal development of the hand and wrist. 2nd ed. California, CA: Stanford University Press 1959. 272 p.

6. Bleka Ø, Wisløff T, Dahlberg PS, Rolseth V, Egeland T. Advancing estimation of chronological age by utilizing available evidence based on two radiographical methods. Int J Legal Med 2018 May 7 [Epub ahead of print].

7. Bookstein FL. Morphometric tools for landmark data: geometry and biology. Cambridge: Cambridge University Press 1991. $435 \mathrm{p}$.

8. Dryden IL, Mardia KV. Statistical shape analysis. Chichester: Wiley 1998.347 p.

9. Ludlow JB, Walker C. Phantom dosimetry and image quality of i-CAT FLX cone-beam computed tomography. Am J Orthod Dentofacial Orthop 2013 Dec;144(6):802-817.

10. Asif MK, Nambiar P, Mani SA, Ibrahim NB, Khan IM, Sukumaran P. Dental age estimation employing CBCT scans enhanced with Mimics software: Comparison of two different approaches using pulp/tooth volumetric analysis. J Forensic Leg Med 2018 Feb;54:53-61.

11. Gulsahi A, Kulah CK, Bakirarar B, Gulen O, Kamburoglu K. Age estimation based on pulp/tooth volume ratio measured on cone-beam CT images. Dentomaxillofac Radiol 2017 Dec 18;47(1):20170239.

12. Koh KK, Tan JS, Nambiar P, Ibrahim N, Mutalik S, Khan Asif M. Age estimation from structural changes of teeth and buccal alveolar bone level. J Forensic Leg Med 20172017 May;48:15-21.

13. Byun BR, Kim YI, Yamaguchi T, Maki K, Son WS. Quantitative assessment of cervical vertebral maturation using cone beam computed tomography in Korean girls. Comput Math Methods Med 2015;2015:405912.

14. Jang HI, Kim SC, Chae JM, Kang KH, Cho JW, Chang NY et al. Relationship between maturation indices and morphology of the midpalatal suture obtained using cone-beam computed tomography images. Korean J Orthod 2016 Nov;46(6):345-355.

15. Chatzigianni A, Halazonetis DJ. Geometric morphometric evaluation of cervical vertebrae shape and its relationship to skeletal maturation. Am J Orthod Dentofacial Orthop 2009 Oct;136(4):481-490.

16. Braga J, Treil J. Estimation of pediatric skeletal age using geometric morphometrics and three-dimensional cranial size changes. Int J Legal Med 2007 Nov;121(6):439-443.

17. Moss ML. The functional matrix hypothesis revisited. 2. The role of an osseous connected cellular network. Am J Orthod Dentofac Orthop 1997 Aug;112(2):221-226.

18. Treil J, Borianne P, Casteigt J, Faure J, Horn A. The human face as a 3-Dimensional model: the future in orthodontics. World J Of Orthod 2001 Dec;2(3):253-257.

19. Wilson-Pauwels L, Akesson EJ, Stewart PA. Cranial nerves anatomy and clinical comments. Philadelphia, PA: BC Decker Inc 1988. 245 p. 
20. Klingenberg CP. MorphoJ: an integrated software package for geometric morphometrics. Molecular Ecology Resources 2011 Mar;11(2):353-357.

21. Gower J. Generalized Procrustes Analysis. Psychometrika 1975 Mar;40(1):33-35.

22. Saadé A, Baron P, Noujeim Z, Azar D. Dental and skeletal age estimations in Lebanese children: A retrospective crosssectional study. J Int Soc Prev Community Dent 2017 MayJun;7(3):90-97.

23. Chaumoitre K, Saliba-Serre B, Adalian P, Signoli M, Leonetti G, Panuel M. Forensic use of the Greulich and Pyle atlas: prediction intervals and relevance. Eur Radiol 2017 Mar; 27(3):1032-1043.

24. Dahlberg PS, Mosdøl A, Ding KY, Bleka Ø, Rolseth V, Straumann GH, Skjerven-Martinsen M, Delaveris GJM, Vist GE. Agreement between chronological age and bone age based on the Greulich and Pyle atlas for age estimation: A systematic review. Oslo, Norway: Knowledge Centre for the Health Services at The Norwegian Institute of Public Health (NIPH); 2017. 121p.

25. Elamin F, Abdelazeem N, Elamin A, Saif D, Liversidge HM. Skeletal maturity of the hand in an East African group from Sudan. Am J Phys Anthropol 2017 Aug;163(4):816-823.
26. Yan-Vergnes W, Vergnes JN, Dumoncel J, Baron P, MarchalSixou C, Braga J. Asynchronous dentofacial development and dental crowding: a cross-sectional study in a contemporary sample of children in France. J Physiol Anthropol 2013 Nov;32(1):22-30.

27. Rhee CH, Shin SM, Choi YS, Yamaguchi T, Maki K, Kim I et al. Application of statistical shape analysis for the estimation of bone and forensic age using the shapes of the 2nd, 3rd, and 4th cervical vertebrae in a young Japanese population. Forensic Sci Int 2015 Dec;257:513.e1-e9.

28. KimSH, Choi YK, Shin SM, Choi YS, Yamaguchi T, TakahashiM et al. The estimation of skeletal maturity of patients with cleft lip and palate using statistical shape analysis: a preliminary study. Dentomaxillofac Radiol 2017 Jul;46(5):20160491.

29. Proffit W, Fields H. Contemporary Orthodontics. $5^{\text {th }}$ ed. Missouri, MI: Mosby 2012. 768 p.

30. Enlow DH, Hans MG. Essentials of Facial Growth. Philadelphia, PA: W.B. Saunders Company 1996. 318 p.

31. Barbeito-Andrés J, Ventrice F, Anzelmo M, Pucciarelli HM, Sardi ML. Developmental covariation of human vault and base throughout postnatal ontogeny. Ann Anat 2015 Jan;197:59-66. 